\title{
The Diversity of Human Dirofilariasis in Western Sri Lanka
}

\author{
T. G. A. N. Chandrasena $\left(\mathbb{D},{ }^{1}\right.$ R. Premaratna, ${ }^{2}$ C. H. Mallawaarachchi, ${ }^{3}$ N. K. Gunawardena, ${ }^{1}$ \\ P. A D. H. N. Gunathilaka $\mathbb{D}^{1},{ }^{1}$ W. Y. Abeyewickrama, ${ }^{4}$ and N. R. de Silva ${ }^{1}$
}

\author{
${ }^{1}$ Department of Parasitology, Faculty of Medicine, University of Kelaniya, Sri Lanka \\ ${ }^{2}$ Department of Medicine, Faculty of Medicine, University of Kelaniya, Sri Lanka \\ ${ }^{3}$ Postgraduate Institute of Medicine, Ministry of Health, Sri Lanka \\ ${ }^{4}$ Colombo South Teaching Hospital, Ministry of Health, Sri Lanka
}

Correspondence should be addressed to T. G. A. N. Chandrasena; nilminicha64@gmail.com

Received 15 February 2019; Revised 25 March 2019; Accepted 4 April 2019; Published 18 April 2019

Academic Editor: Francesca Mancianti

Copyright (c) 2019 T. G. A. N. Chandrasena et al. This is an open access article distributed under the Creative Commons Attribution License, which permits unrestricted use, distribution, and reproduction in any medium, provided the original work is properly cited.

\begin{abstract}
Background. Human dirofilariasis is an emerging zoonosis in many countries. Dirofilariasis caused by Dirofilaria repens may present with diverse clinical manifestations in humans due to aberrant localization of worm lesions causing diagnostic dilemmas. The aim of this retrospective study was to describe and update the demography and clinical spectrum of human dirofilariasis in western Sri Lanka. Nematode or nematode fragments isolated from excision biopsies that were confirmed as D. repens at the Department of Parasitology, Faculty of Medicine, University of Kelaniya, Sri Lanka, between 2012 and 2018 were included. Data on age, gender, and clinical details were obtained from case files. Identity of worms was established by morphometry and cuticle characteristics on wetmount preparation. Specimens from unusual case presentations were further analyzed by PCR with specific primers for internal transcribed spacer region 2 (ITS2) of the ribosomal DNA. Results. Sixteen nematode specimens isolated from subconjunctiva ( $\mathrm{n}=2$ ), subcutaneous $(\mathrm{n}=13)$ and intramuscular $(\mathrm{n}=1)$ locations were identified as $D$. repens by morphometry (average length $11.5 \mathrm{~cm}$ ) and the characteristic longitudinal striations on cuticle visualized by microscopy. The age distribution of cases ranged from 1 to 65 years with a mean of 21.5. Females were more frequently affected $(n=10,62.5 \%)$ and worm locations were commonest in the orbital region (5/16) and scrotum (3/16). Imaging techniques were of use in detecting infections in deeper tissue levels. PCR analysis of DNA extracted from a worm in an intramuscular granuloma of the temporal region elicited the expected band at $484 \mathrm{bp}$ for $D$. repens. Conclusions. Human dirofilariasis is on an upward trend in incidence. Imaging techniques were of use in clinical diagnosis and molecular speciation in establishing the species identity in unusual case presentations. We suggest a more conservative approach in the management of human dirofilariasis and recommend a one health approach for control.
\end{abstract}

\section{Background}

Dirofilariasis is a group of zoonotic filarial infections mainly of dogs (natural host), cats, and other carnivores. Two species are mostly of relevance with regard to human infections, Dirofilaria (Nochtiella) repens and D. immitis $[1,2]$. In the natural definitive hosts (dogs), the adult worms of $D$. repens are mainly found in the subcutaneous tissues and D. immitis infections are related to the presence of adult worms in the pulmonary artery and right ventricle of hearts while microfilaria of both species are usually found in the blood stream.

The life cycle of Dirofilaria species is similar to that of other filarial parasites, with a definitive vertebrate host and a vector. Both $D$. immitis and D. repens demonstrate low vertebrate host specificity as they are able to infect numerous mammalian species. They are best adapted to canines but cats also can act as reservoirs of $D$. (N.) repens [2]. Humans are regarded as less suitable hosts as parasites usually do not mature sufficiently to produce microfilaraemia. But occasional reports of subcutaneous dirofilariasis with circulating microfilaraemia in humans contradict the commonly accepted belief that humans are dead-end hosts $[2,3]$.

Vectors comprise female mosquitoes of the Culicidae family [4]. Both D. repens and D. immitis themselves are hosts to essential symbiotic bacteria of the genus Wolbachia that has been shown to play an important role in filarial biology and host-parasite interactions [5]. 
Of the two species, D. immitis is more widespread in distribution, involving tropical and temperate regions of the Old World as well as the New World [6] while D. repens is limited to Asia, Africa, and Europe [2, 7]. At present dirofilariasis is regarded as an emerging zoonosis in many countries [2, 7-9].

Human infections with $D$. repens commonly affect the subcutaneous or subconjunctival tissues while $D$. immitis is associated with pulmonary dirofilariasis [10]. However, $D$. repens may infect a variety of anatomical sites including the peritoneum, omentum, lungs, and soft tissues (breasts and muscles) [11-14]. Transient inflammatory swellings or nodules signal the presence of worms while in more sensitive tissues such as conjunctiva an acute inflammatory response occurs prompting immediate medical attention [10].

Subcutaneous and ocular dirofilariasis caused by $D$. repens is one of the most frequently detected parasitic zoonosis in Sri Lanka $[15,16]$. On the other hand, cardiopulmonary dirofilariasis caused by $D$. immitis has not been described in Sri Lanka to date. A global review of cases from 1995 to 2000 has documented the second largest collection of subcutaneous and ocular D. repens infections from Sri Lanka [11]. Subsequently a series of intraoral infections were reported in 2003 [17] and 2015 [18] and 30 cases of ocular infections were reported from 2006 to 2014 from the central province of Sri Lanka [16]. Moreover, the prevalence of canine and feline $D$. repens infections continues to be high in western Sri Lanka $[19,20]$.

Differentiation of worm granulomata from other causes of nodules is an important aspect in the clinical management of human dirofilariasis. Thus surgery is recommended, mostly to exclude a malignant origin of a nodule or for removal of worms in ocular locations. Chemotherapy is usually not practiced [21]. Although most infections cause minor disease, serious consequences ranging between impaired or loss of vision and meningoencephalitis have occurred $[2,12]$.

The diversity of human $D$. repens disease manifestations has often caused diagnostic dilemmas [22]. This study provides an update on the epidemiology and diversity of disease manifestations of $D$. repens infections in western Sri Lanka.

\section{Methods}

This retrospective case analysis was conducted from 2012 to 2018 in the Department of Parasitology, Faculty of Medicine, University of Kelaniya, Sri Lanka. All excision biopsy specimens from which the entire nematode or nematode fragments were extracted were included. Worm identity was established by morphometry and the presence of longitudinal striations on cuticle visualized in wet-mount preparations by microscopy [10, 23]. Molecular speciation of extracted worm specimens was performed on an unusual case presentation of an intramuscular worm granuloma (case No. 16 in Table 1).

Extraction of genomic DNA from worm fragments was performed using the Qiagen minikit (Qiagen DY14, Hilden, Germany) as per manufacturer's instructions. The extracted DNA was analyzed by PCR using pan-filarial primers (DIDRF1 5'-AGT GCG AAT TGC AGA CGC ATT GAG-3' and

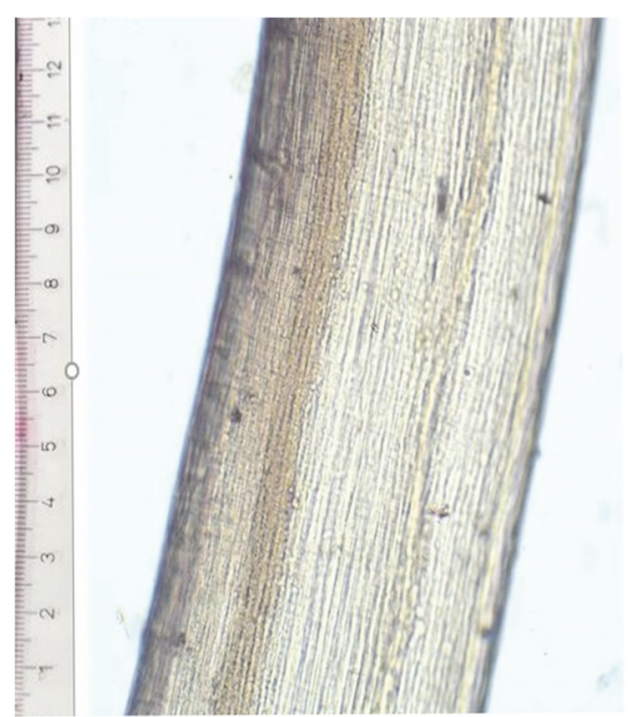

FIGURE 1: The cuticle of D. repens as visualized by light microscopy. The longitudinal striations on the cuticle of D. repens (x10).

DIDR-R1 5'-AGC GGG TAA TCA CGA CTG AGT TGA-3') specific for the internal transcribed spacer region 2 (ITS2) of the ribosomal DNA [24]. Electrophoresis of the PCR products was done on $2 \%$ agarose gel.

The demographic and clinical data that was retrieved from case files or referral letters or by direct contact with patients were analyzed. Written informed consent was obtained to publish clinical, laboratory, and imaging data of relevant patients (cases: 13 and 16, Table 1).

\section{Results}

A total of 16 case referrals were confirmed as D. repens infection. The age distribution of cases varied from 1 to 65 years with a mean of 21.5. Nematode specimens were extracted from subconjunctival $(n=2)$, subcutaneous $(n=13)$, and intramuscular tissues $(n=1)$. Worms were mostly extracted from the orbital region (6/16) and scrotum (3/16) as shown in Table 1 . All worms were identified as $D$. repens by morphometry (average length $11.5 \mathrm{~cm}$ ) and the characteristic longitudinal cuticular striations (see Figure 1). Molecular speciation of the worm specimen extracted from the left superficial temporalis muscle (case No. 16) by PCR elicited the expected band at $484 \mathrm{bp}$ confirming the identity of the worm as D. repens (Figure 2).

Brief descriptions of the two aberrant case presentations are included to make clinicians aware of such manifestations.

3.1. Migrating Worm in the Eye (Case No. 13 in Table 1). A 34-year-old female resident from Seeduwa (a semiurban area located $25 \mathrm{~km}$ north of Colombo, along the western coastal belt of Sri Lanka) presented to the ophthalmology clinic in 2016 with a history of itchiness and sensation of a foreign body in the left eye for several hours followed by sighting of a worm migrating across the eye. 
TABLE 1: Demography and clinical details of confirmed D. repens infections (2012-2018).

\begin{tabular}{|c|c|c|c|c|c|c|}
\hline Case no. & Year & Worm Location & Symptoms & Age (year) & $\begin{array}{l}\text { Gender } \\
\mathrm{M}^{\mathrm{a}} / \mathrm{F}^{\mathrm{b}}\end{array}$ & $\begin{array}{c}\text { Worm species \& } \\
\text { comments }\end{array}$ \\
\hline 1 & 2012 & $\begin{array}{l}\text { Encysted } \\
\text { Conjunctiva }\end{array}$ & $\begin{array}{c}\text { Redness, tearing of } \\
\text { left eye }\end{array}$ & 65 & $\mathrm{~F}$ & D.repens Live \\
\hline 2 & 2013 & $\begin{array}{l}\text { Subcutaneous, } \\
\text { right buttock }\end{array}$ & $\begin{array}{l}\text { Lump on the right } \\
\text { buttock }\end{array}$ & 8 & M & D.repens Dead \\
\hline 3 & 2013 & Conjunctiva & $\begin{array}{c}\text { Redness, itching of } \\
\text { left eye }\end{array}$ & 18 & $\mathrm{~F}$ & D.repens Dead \\
\hline 4 & 2013 & $\begin{array}{c}\text { Subcutaneous } \\
\text { Infraorbital }\end{array}$ & Cystic lump & 20 & $\mathrm{~F}$ & D.repens Dead \\
\hline 5 & 2014 & $\begin{array}{l}\text { Subcutaneous, left } \\
\text { index finger }\end{array}$ & Cystic lump & 14 & $\mathrm{~F}$ & $\begin{array}{c}\text { D.repens Dead } \\
\text { encysted in a sac }\end{array}$ \\
\hline 6 & 2015 & $\begin{array}{c}\text { Subcutaneous, } \\
\text { Infraorbital }\end{array}$ & Lump & 20 & $\mathrm{~F}$ & D.repens Dead \\
\hline 7 & 2015 & $\begin{array}{l}\text { Subcutaneous, } \\
\text { scrotum }\end{array}$ & Lump & 1 & M & D.repens Live \\
\hline 8 & 2016 & $\begin{array}{l}\text { Subcutaneous, } \\
\text { Infraorbital }\end{array}$ & Lump & 46 & $\mathrm{~F}$ & D.repens Dead \\
\hline 9 & 2016 & $\begin{array}{l}\text { Subcutaneous, } \\
\text { left forearm }\end{array}$ & Cystic lump & 2 & $\mathrm{~F}$ & D.repens Live \\
\hline 10 & 2016 & $\begin{array}{l}\text { Subcutaneous, } \\
\text { Scrotum }\end{array}$ & Lump & 16 & M & D.repens live Female \\
\hline 11 & 2016 & $\begin{array}{l}\text { Subcutaneous, } \\
\text { Scrotum }\end{array}$ & Lump & 46 & M & D.repens Live \\
\hline 12 & 2016 & $\begin{array}{l}\text { Subcutaneous } \\
\text { Abdominal wall }\end{array}$ & Lump & 2 & $\mathrm{~F}$ & D.repens Dead \\
\hline 13 & 2016 & $\begin{array}{c}\text { Ocular and } \\
\text { subcutaneous } \\
\text { Abdominal wall }\end{array}$ & Migratory worm & 34 & $\mathrm{~F}$ & D.repens Live \\
\hline 14 & 2017 & $\begin{array}{l}\text { Subcutaneous } \\
\text { Thigh }\end{array}$ & Lump & 14 & M & D.repens Dead \\
\hline 15 & 2018 & $\begin{array}{c}\text { Subcutaneous } \\
\text { Neck }\end{array}$ & Cystic lump & 2 & M & $\begin{array}{c}\text { D.repens Dead } \\
\text { encysted in an abscess }\end{array}$ \\
\hline 16 & 2018 & $\begin{array}{c}\text { Intramuscular, } \\
\text { Superficial } \\
\text { temporalis muscle }\end{array}$ & $\begin{array}{l}\text { Inflammatory mass } \\
\text { temporomandibular } \\
\text { joint }\end{array}$ & 36 & $\mathrm{~F}$ & $\begin{array}{c}\text { D. repens } \\
\text { fragmented worm }\end{array}$ \\
\hline
\end{tabular}

a, Male.

b, Female.

At the clinic the worm was visualized by slit lamp examination but extraction failed as the worm migrated to the periorbital tissues. The following day, the patient presented to the Department of Parasitology with periophthalmitis (periorbital swelling, intermittent tearing, and red eye) for which a course of doxycycline (anti-Wolbachia agent) was administered combined with steroids. The ophthalmitis subsided but she experienced transient itchiness over the face and chest area. On the fifth day of treatment, an adult $D$. repens worm emerged from a "pimple" like lesion on the anterior abdominal wall accidently punctured by the patient herself (Figure 3).
3.2. Intramuscular Dirofilariasis in the Temporal Region Presenting as a Soft Tissue Mass (Case No.16). A 36-yearold female medical officer residing in Colombo presented in 2018 with trismus, deviation of the mouth to a side, and mild swelling over the left temporomandibular joint (LTMJ). The swelling worsened following a molar extraction (incidental to the main pathology) and administration of intravenous antibiotic and amoxicillin/clavulanate resulted in its remission leaving a localized nodule $3 \mathrm{~cm}$ in size over the LTMJ which was accompanied by systemic symptoms of giddiness, nausea, vomiting, and severe headache. 


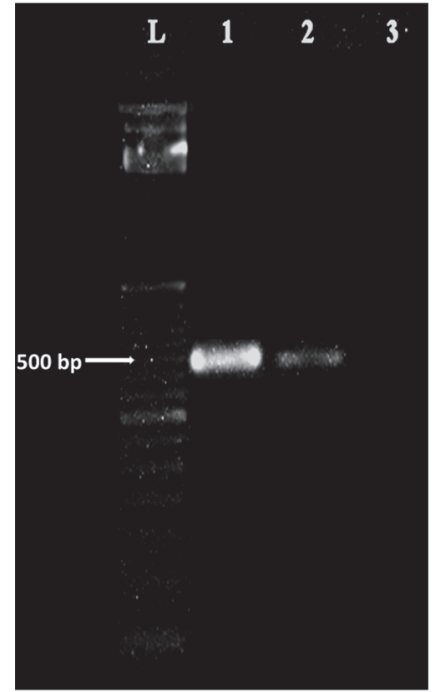

FIGURE 2: Gel-image of PCR amplified products with pan-filarial primers, DIDR-F1 5' and DIDR-R1 5'. Lanes L -100bp marker, 1- D. repens positive control, 2- case no. 16, and 3- negative control.

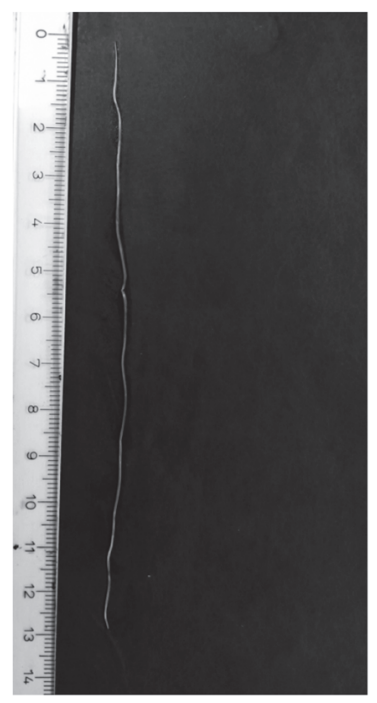

Figure 3: An adult D. repens worm. The worm extracted from the abdominal lesion in case no. 13.

A contrast-enhanced MRI scan of the head revealed the presence of a contrast-enhancing tubular tortuous structure with a large area of oedema in the surrounding soft tissues, suggestive of inflammation (see Figure 4(a)). The imaging findings together with a mild peripheral blood eosinophilia (5.9\%, reference range $0.5-5)$ raised the possibility of an underlying parasitic granuloma. Ultrasonography of the region also revealed the presence of a tubular hyperechoic lesion $(2.2 \mathrm{~cm} \times 0.7 \mathrm{~cm} \times 0.5 \mathrm{~cm})$ within the left superficial temporalis muscle. Lack of movements of the tubular structure suggested a dead worm. Administration of antifilarials for a week \{diethylcarbamazine citrate (DEC) $6 \mathrm{mg} / \mathrm{kg}$, albendazole $200 \mathrm{mg}$ and doxycycline $100 \mathrm{mg}$ twice daily\} resulted in minimal clinical improvement. A dose of intravenous

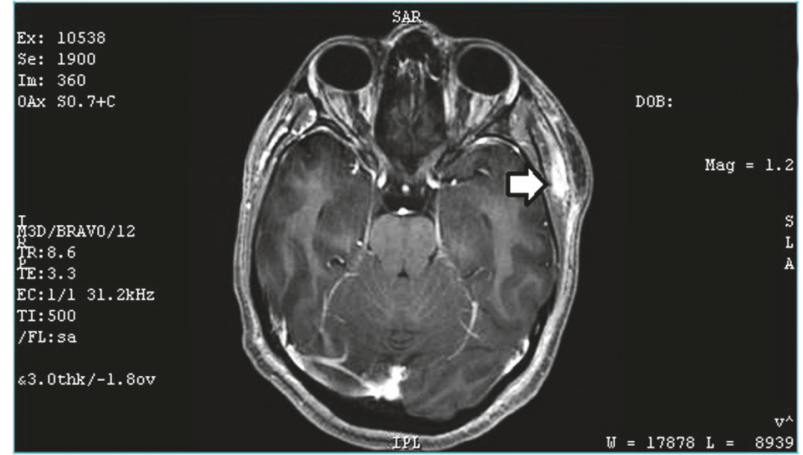

(a)

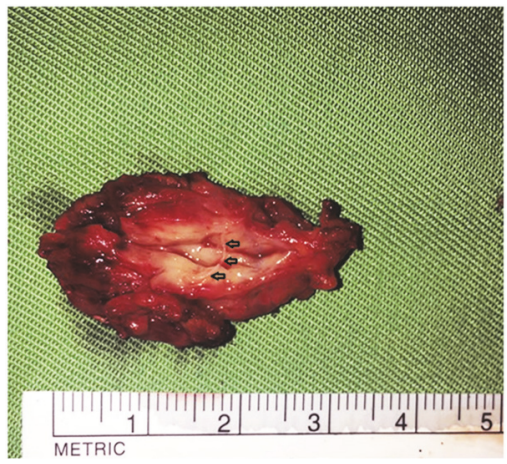

(b)

FIGURE 4: (a) MRI scan image of the brain of case 16. The scan image shows the contrast-enhancing tubular structure in the left temporal region with involvement of the superficial temporalis muscle (thick arrow head). (b) Gross aspect of the excised worm granuloma in case 16. Worm fragments (arrowheads) are visualized within the dissected specimen.

steroid and dexamethasone provided partial remission but symptoms recurred with cessation of therapy.

Excision was done under general anaesthesia with an incision placed $2 \mathrm{~cm}$ posterior to the hairline. A sausage shaped lump with ill-defined margins, $3 \mathrm{~cm} \times 1.5 \mathrm{~cm} \times 0.7$ $\mathrm{cm}$ in size, was removed by incising the superficial temporalis muscle (Figure $4(\mathrm{~b})$ ). Whitish worm fragments $2-3 \mathrm{~cm}$ in size were noted within the dissected specimen. Recovery was uneventful with a small residual nodule on the LTMJ.

\section{Discussion}

A combination of conventional microscopy and molecular techniques was applied in the confirmation of $D$. repens infections at a reference laboratory situated in western Sri Lanka. The frequency of $D$. repens isolations in the present series appears to follow an upward global trend.

Similar to past reviews, subcutaneous dirofilariasis commonly manifested as solitary nodules and less frequently as migratory swellings in this series (Table 1) [11]. Females were more frequently affected as reported in the past $(10 / 16 ; 62.5 \%)$ $[11,16]$. In accordance with the world literature the majority of lesions $(10 / 16 ; 62.5 \%)$ were located on the upper half of 
the body $[11,16]$, with the face being the commonest site affected $(7 / 16 ; 43.75 \%)$. In the lower half of the body, scrotum was a favored location $(3 / 16 ; 18.8 \%)$ as reported in the past by Dissanaike et al. [15]. The aggregation of lesions on the upper half of the body has been explained by the tendency for parasites to locate near points of mosquito bites [1] which are higher on exposed regions such as face, neck, and upper limbs. The reason for favoring scrotal tissues is unknown and appears to be unique to Sri Lankan cases [15].

The deeper tissue level infections have been attributed to the tendency for adult/immature worms to migrate within soft tissues until restricted by host defenses at its final anatomical location [1]. The common age groups affected in the present series were the $1-10(5 / 16 ; 31.2 \%)$ and $11-20$ $(6 / 16 ; 37.5 \%)$ years' age groups, which was somewhat similar to that reported by Dissanaike et al. in the past (less than 9 years) [15] but was much younger than the common age group of 40-49 years, reported by Iddawela et al. for ocular dirofilariasis in the cooler climes of the central province of Sri Lanka [16] and those reported from the European region (40-49 years) [11]. Perhaps the practice of leaving children minimally clothed because of the warm and humid weather in the western region may have exposed them more to mosquito bites and infection.

Worldwide, seven cases of dirofilariasis with localization in the temporal region have been described up to 2017 [14]; only two of them were in intramuscular locations [11, 14]. Thus this case series documents the third case of intramuscular dirofilariasis of the temporal region caused by D. repens. Therefore, it is important to consider dirofilariasis in the differential diagnosis of soft tissue masses located at deeper levels. Ocular dirofilariasis in the present series involved the infraorbital and subconjunctival tissues but none were in intraocular tissues, which is documented as uncommon [25].

Surgical extraction of worms from superficial tissues or from the conjunctiva is a simple procedure but intervention is more complex in the case of internal locations especially in the head and neck regions. With the advent of advanced imaging techniques which enable differentiation of worm granulomata from other nodules/masses with a high degree of accuracy [26] and the discovery of an important therapeutic target (essential symbiont, Wolbachia) [27, 28], a more conservative management approach may be feasible. It is documented that administration of DEC does not kill the worms, but arrests their migration and causing them to settle at one spot, after which they emerged from lesions spontaneously or by application of pressure on lesions (squeezing) [15]. A similar outcome was observed with doxycycline treatment in case no. 13 of the present series. The outcome of chemotherapy in the intramuscular infection (case no. 16) differed. It is possible that the death of the worm in this case was mediated by the host's immune response [10]. This theory is supported by the ultrasonographic findings which suggested a dead worm. The secondary inflammatory response initiated by the lipopolysaccharide-like activity of the symbiotic Wolbachia bacteria, released from the tissues of the dead worm [29-31], may have initiated the pathological manifestations. Thus, administration of filaricides (DEC and albendazole) and Wolbachia clearing agents (doxycycline) provided minimal improvement at that stage but steroid therapy provided remission of symptoms as in the case reported by Poppert et al. [12]. With the rising incidence it would be timely to explore the place of chemotherapy that may result in regression of worm granulomata without surgical intervention.

This retrospective survey was based on referrals of worms or worm fragments to a single center in western Sri Lanka and thereby is limited in its ability to reflect the dirofilariasis situation in the entire country. Even regionally it portrays only the "tip of the iceberg" as histological referrals were not included in the current series due to difficulties encountered in data retrieval. The recent spurt of infections may also set a trend for by-passing referrals for parasitological diagnosis. Thus, many cases may remain undiagnosed and go unreported. Another drawback in this case series was the application of molecular speciation only on two specimens. However, worm identification on gross features is reliable provided the intact worm is recovered from tissues [10].

Currently human dirofilariasis is a low priority infection with scant attention being focused on control, perhaps because most infections cause only minor disease as in the current case series. However, the psychological impact of infection during the acute phase was immense because the idea of harboring migrant worms was very distressing. Ocular infections were particularly worrying due to potential visual complications.

Recent environmental modifications in the western province of Sri Lanka such as creation of water bodies within city limits as part of storm water management projects may have increased vector abundance and development of landfill sites in the suburbs for human habitation increased their exposure to infection. The zoonotic reservoir of infection [19,20] and low levels of public awareness in the western province of Sri Lanka (18.5\%) [19] are other factors contributing towards the rise in infections. Controlling canine and feline dirofilariasis by chemotherapy/chemoprophylaxis as well as reduction of vector populations are mandatory measures in combating the rise of human dirofilariasis. These two strategies may also provide a bonus effect in arresting the spread of Brugia malayi (subperiodic) of probable zoonotic origin that has emerged in Sri Lanka during the postelimination era of lymphatic filariasis [32].

\section{Conclusions}

Human dirofilariasis continues on an upward trend in incidence in Sri Lanka with diverse manifestations which included a case of $D$. repens infection in the temporal region with intramuscular localization of the worm. Imaging techniques were of use in clinical diagnosis and molecular speciation in establishing the species identity in such unusual case presentations. We suggest a more conservative approach in the management of human dirofilariasis and recommend close collaboration with medical doctors and veterinarians for control of human dirofilariasis. 


\section{Abbreviations}

ITS: Internal transcribed spacer region

PCR: Polymerase chain reaction

DNA: Deoxyribonucleic acid

LTMJ: Left temporomandibular joint

DEC: Diethylcarbamazine citrate.

\section{Data Availability}

The data used to support the findings of this study are included within the article.

\section{Ethical Approval}

The Ethics Review Committee of the Faculty of Medicine, University of Kelaniya, Sri Lanka, approved the project protocol (authorization no. P/24/02/2019).

\section{Consent}

Informed written consent was obtained for publication of case descriptions.

\section{Conflicts of Interest}

The authors declare that they have no conflicts of interest.

\section{Authors' Contributions}

R. Premaratna initiated the study, T. G. A. N. Chandrasena, P. A D. H. N. Gunathilaka, N. K. Gunawardena, and W. Y. Abeyewickrama collected and evaluated the data. C. H. Mallawaarachchi and P. A D. H. N. Gunathilaka provided experimental support. T. G. A. N. Chandrasena wrote the manuscript, and R. Premaratna and N. K. Gunawardena edited the manuscript. Final editing was done by N. R. de Silva. All authors read and approved the final manuscript.

\section{Acknowledgments}

The authors acknowledge the technical support extended by the technical officers of the Department of Parasitology, Mr. H. A. Sudusinghe, Mr. W. Nilaweera, temporary demonstrator, Mr. A. C. T. Wijerathna, and the corporation extended by the patients in documenting their cases.

\section{References}

[1] S. Pampiglione, G. Canestri Trotti, and F. Rivasi, "Human dirofilariasis due to Dirofilaria (Nochtiella) repens: a review of world literature," Parassitologia, vol. 37, no. 2-3, pp. 149-193, 1995.

[2] F. Simón, M. Siles-Lucas, R. Morchón et al., "Human and animal dirofilariasis: the emergence of a zoonotic mosaic," Clinical Microbiology Reviews, vol. 25, no. 3, pp. 507-544, 2012.

[3] C. Genchi, L. Rinaldi, M. Mortarino, M. Genchi, and G. Cringoli, "Climate and Dirofilaria infection in Europe," Veterinary Parasitology, vol. 163, no. 4, pp. 286-292, 2009.
[4] G. Cancrini and L. Kramer, "Insect vectors of Dirofilaria spp," in Heartworm Infection in Humans and Animals, F. Simon and C. Genchi, Eds., pp. 63-82, Ediciones Universidad de Salamanca, Spain, 2001.

[5] C. Genchi, L. H. Kramer, D. Sassera, and C. Bandi, "Wolbachia and its implications for the immunopathology of filariasis," Endocrine, Metabolic \& Immune Disorders-Drug Targets, vol. 12, no. 1, pp. 53-56, 2012.

[6] J. W. McCall, C. Genchi, L. H. Kramer, J. Guerrero, and L. Venco, "Heartworm disease in animals and humans," Advances in Parasitology, vol. 66, pp. 193-285, 2008.

[7] C. Genchi and L. Kramer, "Subcutaneous dirofilariosis (Dirofilaria repens): an infection spreading throughout the old world," Parasites \& Vectors, vol. 10, no. S2, 2017.

[8] P. Babal, D. Kobzoa, I. Novak, P. Dubinsky, and N. Jalili, "Fist case of cutaneous human dirofilariasis in Slovak Republic," Bratisl Lek Listy, vol. 109, pp. 485-488, 2008.

[9] R. G. Kini, J. B. Leena, P. Shetty, R. H. Lyngdoh, D. Sumanth, and L. George, "Human dirofilariasis: an emerging zoonosis in India," Journal of Parasitic Diseases, vol. 39, no. 2, pp. 349-354, 2015.

[10] T. C. Orihel and M. L. Eberhard, “Zoonotic Filariasis," Clinical Microbiology Reviews, vol. 11, no. 2, pp. 366-381, 1998.

[11] S. Pampiglione and F. Rivasi, "Human dirofilariasis due to Dirofilaria (Nochtiella) repens: an update of world literature from 1995 to 2000," Parassitologia, vol. 42, no. 3-4, pp. 231-254, 2000.

[12] S. Poppert, M. Hodapp, A. Krueger et al., "Dirofilaria repens infection and concomitant meningoencephalitis," Emerging Infectious Diseases, vol. 15, no. 11, pp. 1844-1846, 2009.

[13] K. Mrad, S. Romani-Ramah, M. Driss et al., "Mammary dirofilariasis: a case report," International Journal of Surgical Pathology, vol. 7, no. 3, pp. 175-178, 1999.

[14] MI. Gheorghita, M. Fortofoiu, CI. Dumitrescu, D. Dumitrescu, A. Camen, and C. Margaritescu, "Intramuscular human Dirofilaria repens infection of the temporal region-case report and review," Romanian Journal of Morphology and Embryology, vol. 58, pp. 585-592, 2017.

[15] A. S. Dissanaike, W. Abeyewickreme, M. D. Wijesundera, M. V. Weerasooriya, and M. M. Ismail, "Human dirofilariasis caused by Dirofilaria (Nochtiella) repens in Sri Lanka," Parassitologia, vol. 39, no. 4, pp. 375-382, 1997.

[16] D. Iddawela, K. Ehambaram, and S. Wickramasinghe, "Human ocular dirofilariasis due to Dirofilaria repens in Sri Lanka," Asian Pacific Journal of Tropical Medicine, vol. 8, no. 12, pp. 1022-1026, 2015.

[17] W. M. Tilakaratne and T. N. Pitakotuwage, "Intra-oral Dirofilariarepens infection: report of seven cases," Journal of Oral Pathology \& Medicine, vol. 32, no. 8, pp. 502-505, 2003.

[18] R. D. Jayasinghe, S. R. Gunawardane, M. A. M. Sitheeque, and S. Wickramasinghe, "A case report on oral subcutaneous dirofilariasis," Case Reports in Infectious Diseases, vol. 2015, Article ID 648278, 4 pages, 2015.

[19] R. P. A. S. Rajapakshe, W. S. R. Perera, R. L. Ihalamulla et al., "Study of dirofilariasis in a selected area in the Western Province," Ceylon Medical Journal, vol. 50, no. 2, pp. 58-61, 2005.

[20] C. H. Mallawarachchi, N. T. Chandrasena, S. Wickramasinghe et al., "A preliminary survey of filarial parasites in dogs and cats in Sri Lanka," PLoS ONE, vol. 13, no. 11, article e0206633, 2018.

[21] F. Simón, J. López-Belmonte, C. Marcos-Atxutegi, R. Morchón, and J. R. Martín-Pacho, "What is happening outside North 
America regarding human dirofilariasis?" Veterinary Parasitology, vol. 133, no. 2-3, pp. 181-189, 2005.

[22] E. Joseph, A. Matthai, L. K. Abraham, and S. Thomas, "Subcutaneous human dirofilariasis," Journal of Parasitic Diseases, vol. 35, no. 2, pp. 140-143, 2011.

[23] N. D. Levine, Nematode Parasites of Domestic Animals and Man, Burgess Publishing Co, Minneapolis, Minn, USA, 1980.

[24] M. Rishniw, S. C. Barr, K. W. Simpson, M. F. Frongillo, M. Franz, and J. L. D. Alpizar, "Discrimination between six species of canine microfilariae by a single polymerase chain reaction," Veterinary Parasitology, vol. 135, no. 3-4, pp. 303-314, 2006.

[25] P. C. Beaver, "Intraocular filariasis: a brief review," The American Journal of Tropical Medicine and Hygiene, vol. 40, no. 1, pp. 4045, 1989.

[26] B. Ilyasov, V. Kartashev, N. Bastrikov et al., "Thirty cases of human subcutaneous dirofilariasis reported in Rostov-on-Don (Southwestern Russian Federation," Enfermedades Infecciosas y Microbiología Clínica, vol. 33, no. 4, pp. 233-237, 2015.

[27] A. Hoerauf, "Filariasis: new drugs and new opportunities for lymphatic filariasis and onchocerciasis," Current Opinion in Infectious Diseases, vol. 21, no. 6, pp. 673-681, 2008.

[28] M. J. Taylor, A. Hoerauf, S. Townson, B. E. Slatko, and S. A. Ward, "Anti-Wolbachia drug discovery and development: safe macrofilaricides for onchocerciasis and lymphatic filariasis," Parasitology, vol. 141, no. 1, pp. 119-127, 2014.

[29] N. W. Brattig, U. Rathjens, M. Ernst, F. Geisinger, A. Renz, and F. W. Tischendorf, "Lipopolysaccharide-like molecules derived from Wolbachia endobacteria of the filaria Onchocerca volvulus are candidate mediators in the sequence of inflammatory and antiinflammatory responses of human monocytes," Microbes and Infection, vol. 2, no. 10, pp. 1147-1157, 2000.

[30] M. J. Taylor, H. F. Cross, and K. Bilo, "Inflammatory responses induced by the filarial nematode Brugia malayi are mediated by lipopolysaccharide-like activity from endosymbiotic Wolbachia bacteria," The Journal of Experimental Medicine, vol. 191, no. 8, pp. 1429-1436, 2000.

[31] F. Tamarozzi, A. Halliday, K. Gentil, A. Hoerauf, E. Pearlman, and M. J. Taylor, "Onchocerciasis: the role of wolbachia bacterial endosymbionts in parasite biology, disease pathogenesis, and treatment," Clinical Microbiology Reviews, vol. 24, no. 3, pp. 459468, 2011.

[32] C. H. Mallawarachchi, T. G. Nilmini Chandrasena, R. Premaratna, S. M. Mallawarachchi, and N. R. De Silva, "Human infection with sub-periodic Brugia spp. in Gampaha District, Sri Lanka: a threat to filariasis elimination status?" Parasites \& Vectors, vol. 11, no. 1, 2018. 


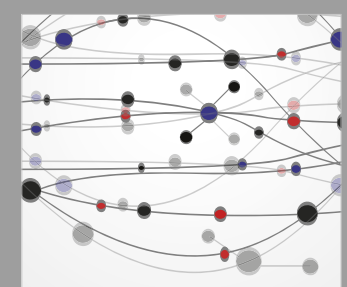

The Scientific World Journal
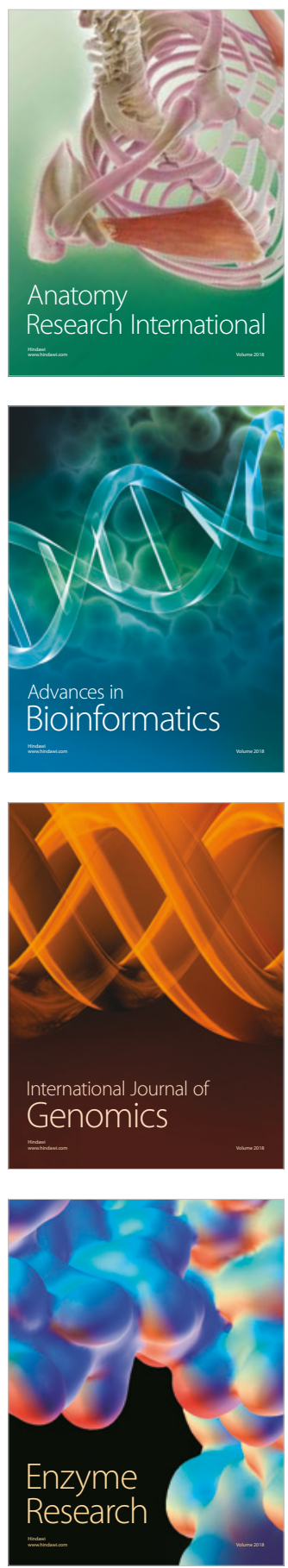
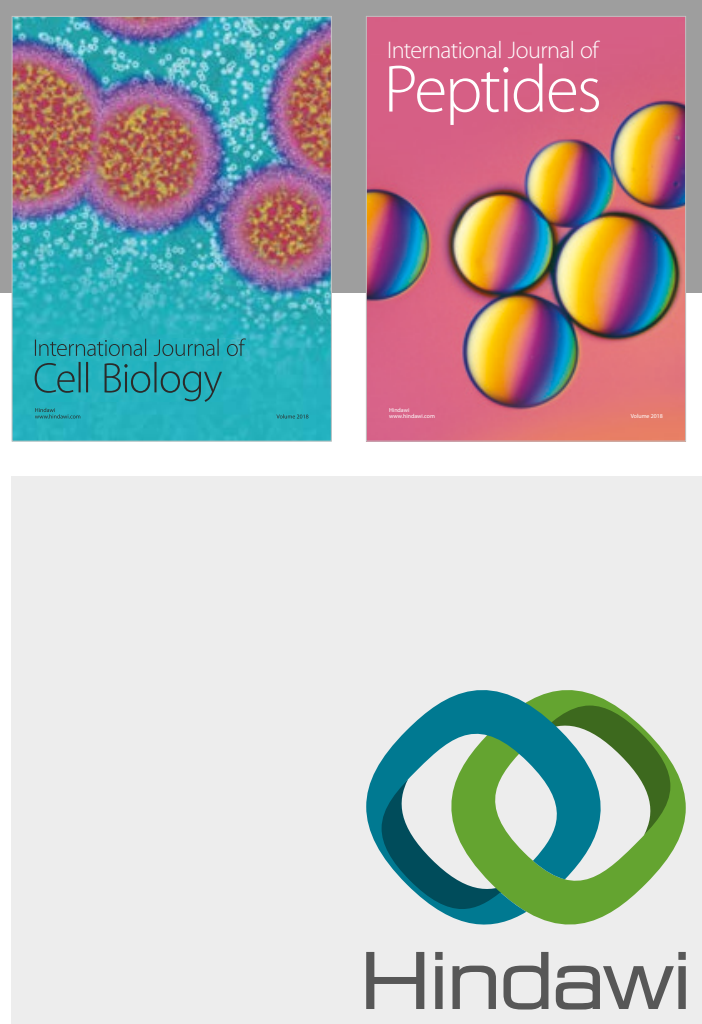

Submit your manuscripts at

www.hindawi.com
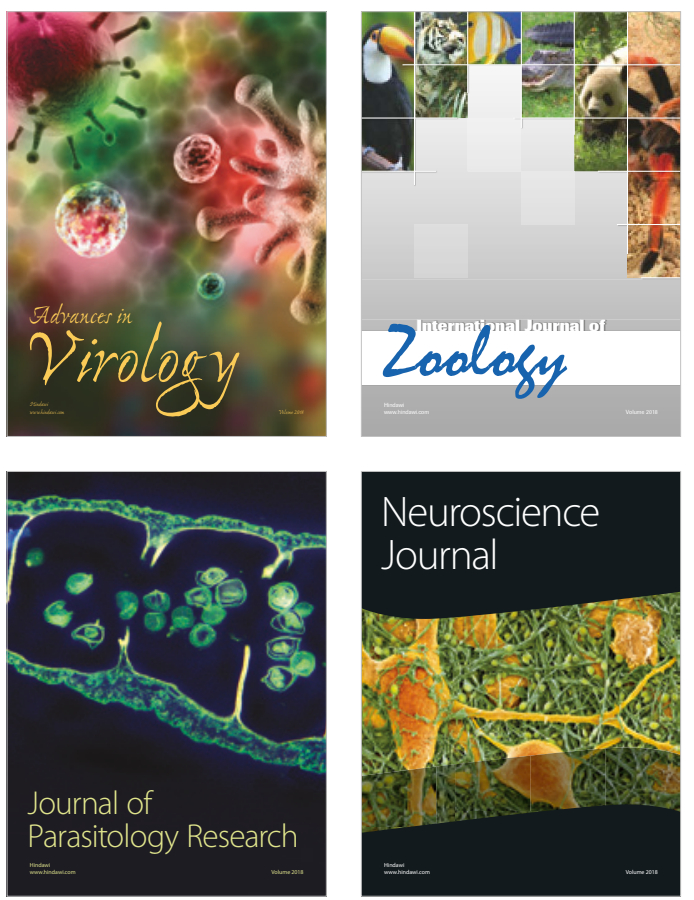
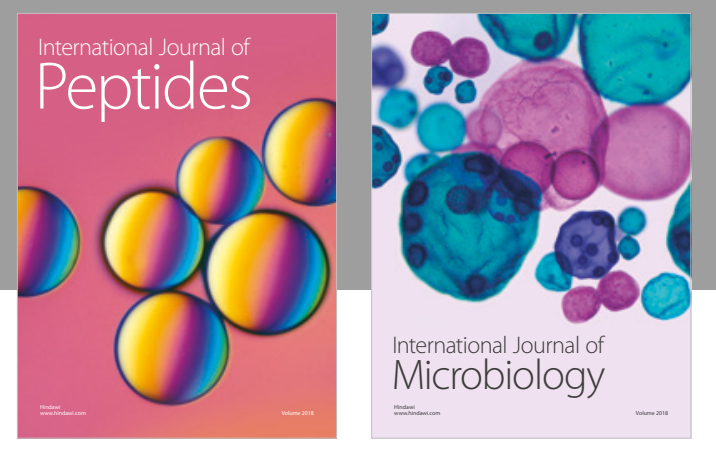

nternational Journal of Microbiology
Journal of
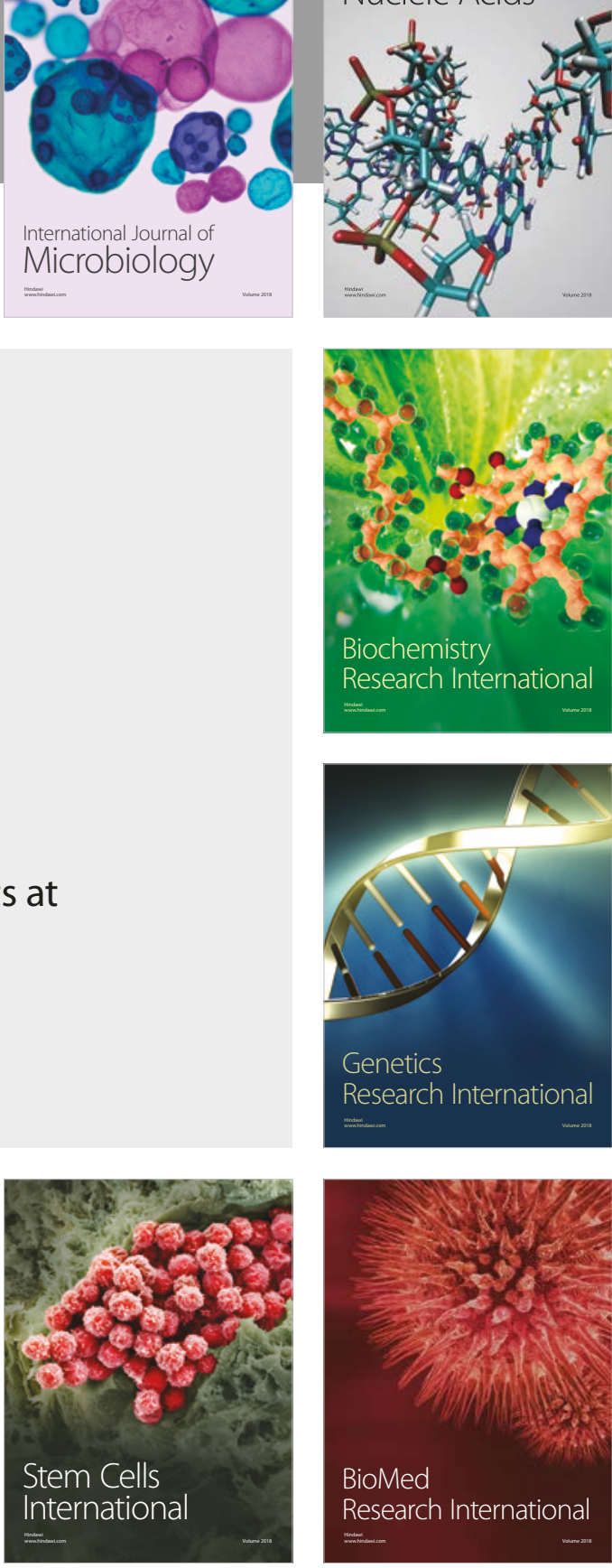
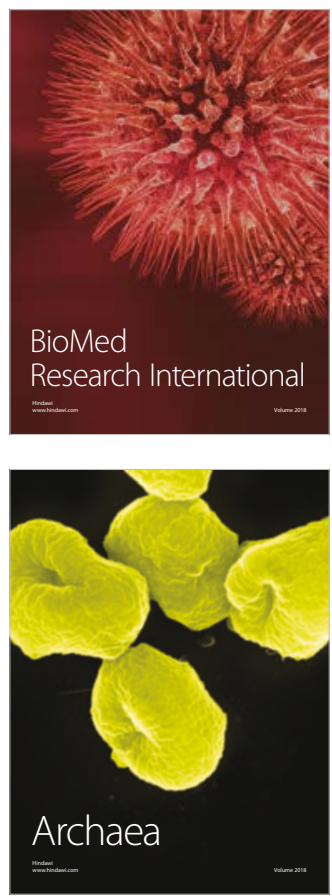